Original Research Paper

\title{
The use of Expected Utility Theory (EUT) in Taxpayers' Behaviour Modelling
}

\author{
Farid Ameur and Mohamed Tkiouat \\ Studies and Research Laboratory in Applied Mathematics (LERMA), \\ Mohammadia School of Engineering, Mohamed V University, Rabat BP 765, Morocco
}

\author{
Article history \\ Received: 14-05-2016 \\ Revised: 12-01-2017 \\ Accepted: 18-01-2017 \\ Corresponding Author: \\ Farid Ameur \\ Studies and Research \\ Laboratory in Applied \\ Mathematics (LERMA), \\ Mohammadia School of \\ Engineering, Mohamed V \\ University, Rabat BP 765, \\ Morocco \\ Tel: +212-642-471-165 \\ Email: ameur_farid@yahoo.fr
}

\begin{abstract}
In this study, we analyze taxpayers' behaviour regarding tax system. We present a theoretical study of a model pre established by other authors based on the expected utility theory; taxpayer's behavior is assumed to be risk-averse. We have released some conditions of this model and we have introduced a new parameter reflecting the efficiency of tax control; we found that the efficiency of a fiscal control have an important effect on these interactions. Previous studies are based on a maximal efficiency of tax control, which is a particular case of our model. We found that for Moroccan case, the fraud is related to the size of companies; it's more important in the big companies than small and medium enterprises. This result can be used as a tool to reconsider administrative approaches of tax compliance.
\end{abstract}

Keywords: Expected Utility Theory, Prospect Theory, Survey, Tax Fraud, Tax Audit, Tax Compliance, Taxpayers, Behaviour,

JEL Classification Codes: H3, C5

\section{Introduction}

A recent study of the determinants of fiscal policy has been published by the Organization for Economic Co-operation and Development (OECD), shows that the tax reforms that have been implemented are designed to respond not only to the need to improve The performance of the economy but also to counter the phenomenon of tax fraud. As for Morocco, the government is undergoing many changes in the tax law. The challenge is to have a competitive and efficient tax system that helps to improve the economic and social environment and tackle the scourge of tax evasion.

The role of tax administration is to end such behavior which changes the social contract. In fact, there is always a difference between the tools and methods of tax fraud and tax audit. However, in order to reduce the cost of this unequal conflict, tax administrations have to be interested in analyzing the behavior of taxpayers so that they can design and implement a more effective set of responses which address the causes of non compliance with tax law.

In this study, we examine this phenomenon based on the model of Allingham and Sandmo (1972) improved by numerous authors such as (Yitzhaki, 1974; Koskela, 1983; Caplin and Leahy, 2001; Bazart, 2002; Ameur and Tkiouat, 2012; 2014; 2015) (the list is not exhaustive).
The literature on tax fraud has shown controversial results. In fact, the proportional taxation of declared income associated with a penalty on dissimulated income $\mathrm{q}^{*}(\mathrm{I}-\mathrm{x})$ is the fundamental hypothesis of the model of Allingham and Sandmo (1972). As such, the taxpayer selects the amount of income to declare, $x$, in order to maximize his expected utility. The results show that increasing the penalty has a positive impact on the honesty of taxpayer on his tax report. However, the difference in declared income compared to the taxation's level ' $t$ ' is undetermined in the Model of Allingham and Sandmo (1972). The question is: Does the proportion of reported income increases as disposable income?

This indetermination was lifted by Yitzhaki (1974) who considered the problem of tax fraud as the one defined by Allingham and Sandmo (1972), but in which the penalty, denoted $\mathrm{q}$, concerns mainly the evaded tax: $t^{*}(I-x)$. The result obtained by Yitzhaki (1974) reveals that the model of expected utility theory forecasts a negative relationship between tax rates and evasion when two conditions are satisfied. First, fines are imposed. Second, the preferences of taxpayers satisfy the decreasing absolute assumption of risk aversion. Several researches consider that such result disagree with the intuition; it was called the "Yitzhaki 
paradox". An empirical literature (Cebula and Feige, 2011) reveals that there is a positive relationship between tax rate and tax fraud.

Kahneman and Tversky (1979) developed a new theory called the Prospect theory based on experimental work. This theory criticizes the expected utility theory (Piolatto and Rablen, 2013; Dhami and Al-Nowaihi, 2007). In fact, the PT provides closer results to the reality than EUT.

Some authors argue that PT can reverse the "Yitzhaki paradox", based on experimental findings; which show a positive relationship between evasion and tax rates. Dhami and Al-Nowaihi (2007) claim that the prospect theory can reverse the "Yitzhaki puzzle". However, the result of (Piolatto and Rablen, 2013) shows that the reference dependent model cannot reverse "Yitzhaki puzzle", when considering that the utility is homogenous. Piolatto and Rablen (2013; Dhami and Al-Nowaihi, 2007), expand their model to include a cost called "stigma", which is related to the possibility of detecting fraud. They conclude that when stigma is equal to zero, the prospect theory cannot reverse the "Yitzhaki puzzle". Also, the "Yitzhaki puzzle" can be inversed when the model of expected utility theory is expanded with stigma.

In the model of Allingham and Sandmo (1972) and in other models developed later, it is supposed that after tax audit, the tax administration has a comprehensive knowledge of the real value of the income chosen by taxpayer. However, in reality, the tax administration is not able to detect all errors and fraud that can be made by a taxpayer in order to reduce his revenue declaration. We proved that the importance of tax fraud, regarding taxpayer income, is related to the penalty ' $\mathrm{q}$ ' and the effectiveness of tax audit which we call ' $r$ '.

In this research, we are going to examine the question of how can EUT or PT explains the fraudulent behavior of taxpayers. Our objective is to be able to identify which Model can better explain the behaviour of taxpayers.

This paper is organized as follows: After the introduction in section 1, we analyze in section 2 the results of some previous studies done by authors who worked on the fraudulent taxpayers' behaviour based on EUT and PT. In section 3, we present our contribution and discussions of the results. We use some examples to show that the result of PT model is not always true. In section 4, we outline the consequences of our theoretical work projected on the Moroccan case to assess the relevance of the last fiscal legislative decisions. In section 5, we conclude this paper by presenting our results and by providing some recommendations that can help in a better understanding of taxpayer's behaviour and improving the effectiveness of tax audit.

\section{Previous Research}

The phenomenon of tax fraud was studied by Allingham and Sandmo (1972) based on the expected utility theory, which was developed in 1944 by John von Neumann and Oskar Morgenstern. The assumptions of Allingham and Sandmo's (1972) model were progressively released by numerous authors, Yitzhaki (1974; Koskela, 1983; Caplin and Leahy, 2001; Bazart, 2002) (the list is not exhaustive). A methodological choice, which is based on observation, represents the main characteristic of those assumptions. This methodology argues that tax evasion's decision is made under uncertainty. The agreement also seems on the parameters which affect the optimal decision of an individual taxpayer.

Yitzhaki (1974) found that, when two conditions are satisfied, the expected utility theory's model predicts a negative relationship between tax rates and evasion. First, fines are imposed and second, the preferences of taxpayers satisfy the declining absolute assumption of risk aversion. Several works consider that there is a contradiction with intuition and this result which was called the "Yitzhaki paradox" or "Yitzhaki puzzle".

Kahneman and Tversky (1979) developed a new theory called the Prospect theory based on experimental work. This theory criticizes the expected utility theory (Piolatto and Rablen, 2013; Dhami and Al-Nowaihi 2007). In fact, the PT provides closer results to the reality than EUT. Some authors argue that PT can reverse the "Yitzhaki paradox", based on experimental findings; which show a positive relationship between evasion and tax rates.

According to Dhami and Al-Nowaihi (2007), the prospect theory has explained the issue of tax evasion in a proper way. Hashimzade et al. (2012) argues that the tax effect's direction is not reversed when applying the prospect theory. Only the selection of tax's level can affect its direction. In order to study the alternatives of a reference-dependent model with the tax evasion's decision.

Piolatto and Rablen (2013) vary the prospect theory's elements that are fixed, the reference of tax level and the audit's probability that may depend on taxpayers' declaration. They then divide the prospect theory into four main elements which are: Reference dependence; the outcomes are refereed according to a reference level of wealth. Then, decreasing sensitivity: It implies a convex preference above the outcomes that are below the reference level and concave preference above the outcomes which are over the reference level. The third element is the disutility of a loss surpasses the utility of a gain. The last element is probability weighting when objectives probabilities are converted to decision weights. 
This decomposition of the prospect theory allows identifying the elements that can inversion the "Yitzhaki pulzze". The results show that the "Yitzhaki pulzze" is not reversed by only introducing the reference dependence when holding the probability of the audit and the reference level fixed. However, both the reference dependence and decreasing sensitivity reverse the "Yitzhaki pulzze" if the payoff is below the reference level. During the analysis process, probability weighting and loss aversion showed that they have no effect to downturn the "Yitzhaki pulzze". Besides, the reference level is enough to reverse the Yitzhaki pulzze if the reference level is sensitive enough to the level of tax rate. However, the "Yitzhaki pulzze" is reversed in case if the reference level is insensitive to the tax rate and when both the decreasing sensitivity and reference level are supposed. According to Piolatto and Rablen (2013), there are some terms of the reference level which are not sensitive enough to the tax rate to inverse the "Yitzhaki pulzze" when taking into consideration only the reference dependence. However, those specifications can be sensitive to the tax rate and reverse the "Yitzhaki pulzze" when combining decreasing sensitivity with reference dependence. Among the specifications of the reference level is when the post-tax wealth of the taxpayer. The reference dependent model cannot reverse the "Yitzhaki pulzze" when utility is set to be concave or to show decreasing sensitivity. These findings are strong in a set of specifications of the reference level like the tax gamble's expected value which permits the dependency of declaration of the taxpayer.

Dhami and Al-Nowaihi (2007) claim that the prospect theory reverses the "Yitzhaki pulzze", but Piolatto and Rablen (2013), when considering that the utility is homogenous, the result was that the reference dependent model cannot reverse Yitzhaki pulzze. Piolatto and Rablen (2013; Dhami and Al-Nowaihi, 2007), expand their model to include a cost called "stigma" related to the possibility of detecting the cheating. They conclude that: The prospect theory cannot reverse the Yitzhaki pulzze when stigma is equal to zero. Also, when the model of expected utility theory is expanded with stigma, it can inverse the Yitzhaki pulzze. Therefore, one cannot conclude that the capacity of reference dependent model to reverse the paradox is greater than the one of the model of expected utility theory.

The authors then argue that the application of the prospect theory to tax evasion fall short when tax evasion increases in the marginal tax rate. New approaches to specify the reference level are then needed.

\section{Our Contribution and Results Discussion}

In this section, we present our methodology and the results obtained. We present our theoretical results; based on previous EUT model. With some modifications of Allingham and Sandmo Model (AS), we argue that despite critics to EUT, PT model isn't more important than EUT.

\section{Critics to Some Previous Results: PT Model Against EUT Model}

All previous researches that criticized the EUT model based their analysis on the fact that the result obtained by the EUT model is against intuition and it is inconceivable that fraud is decreasing as a function of tax rates (Piolatto and Rablen, 2013; Dhami and AlNowaihi, 2007). The position of these researchers was motivated by some surveys and investigations.

Indeed, if we consider that the result obtained by the EUT is against intuition, it means that all taxpayers have the same behaviour; they suppose that tax rate is the most important parameter that influences their behaviour regardless of the degree of tax compliance of each taxpayer. The following example can describe more this point:

We consider two taxpayers $\mathrm{C} 1$ and $\mathrm{C} 2$, the first is known by his honesty and tax compliance. All adjustments that $\mathrm{C} 1$ did after different tax audits were the results of errors or omissions, no fraud was raised. $\mathrm{C} 1$ is satisfied that these contributions allow the state to provide services to citizens and therefore an increase in tax revenues that automatically create more services. He is willing to contribute as far as the contribution does not exceed a given limit. The second taxpayer considers that the tax is a violation of his rights because the state does not give him a real part against his contribution. C2 always seeks the opportunity to minimize his contribution; in particular a decrease in the amount of the penalty may encourage him to increase his fraud. If we place a policy to reduce tax rate:

For C1: The state will lose some of these revenues without any effect on the behaviour of the taxpayer.

For C2: The state will lose some of these revenues since the effect of the decrease in tax penalty encourages him to increase his fraud. We conclude that more a value of tax rate (that we name optimum rate top); tax fraud increase as a function of tax rate. However, tax fraud decrease or doesn't change in function of tax rate.

We can schematize this result in the following graph:

\section{EUT Model with Some New Assumptions}

\section{EUT Model}

To use the advanced of the model of Allingham and Sandmo (1972), taxpayer's behavior is consistent with the axioms of von Neumann-Morgenstern utility function and is solely dependent on disposable income. The taxpayer is assumed to be risk-averse thus this function has a positive marginal utility and strictly decreasing. 

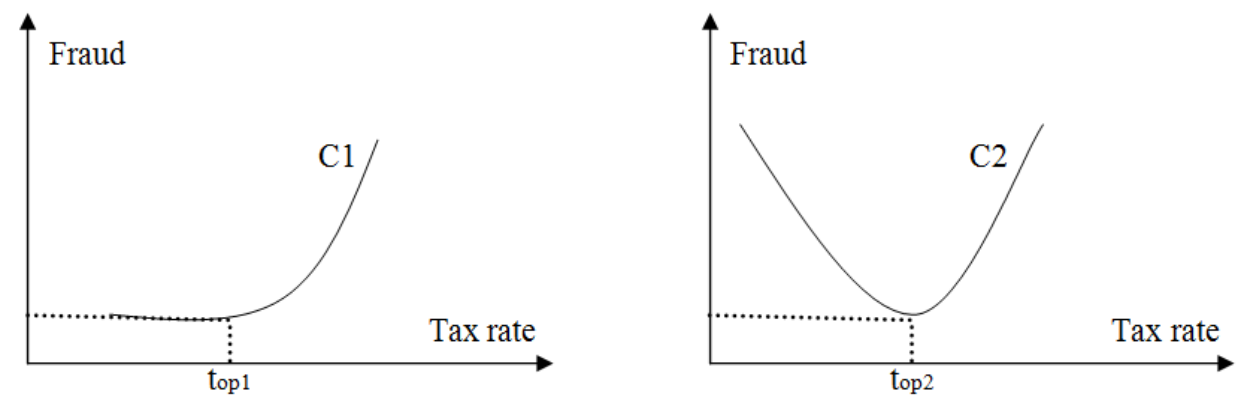

Fig. 1. Tax fraud as a function of tax rate for $\mathrm{C} 1$ and $\mathrm{C} 2$
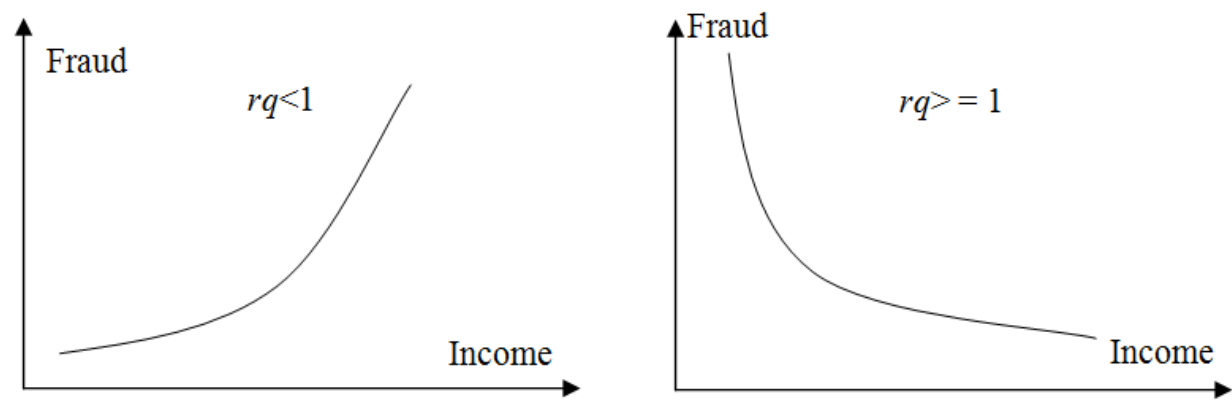

Fig. 2. Tax fraud as a function of income where $r q<1$ and $r q>=1$

The model of Allingham and Sandmo (1972) is given by:

$$
E U=(1-p) U\left(I_{n d}\right)+p U\left(I_{d}\right)
$$

With:

$$
I_{d}=I-t x-q(I-x)
$$

and

$$
I_{n d}=I-t x
$$

While:

$I=$ Real income of the taxpayer, here is an exogenous variable and is known but ignored by the taxpayer of the tax administration

$I_{n d}=$ Disposable income where the taxpayer is not found in the fraud

$I_{d}=$ Disposable income after the tax audit of the taxpayer

$x=$ Income declared decision variable of the taxpayer

$t=$ Tax rate, constant on the amount of reported income, $\mathrm{x}$

$q=$ The rate of penalty for unreported income

$p=$ The probability of detection. It is assumed that after the fiscal control, tax administration has a comprehensive knowledge of the actual amount of taxpayer's income

\section{Previous Results are a Special Case of our Contribution}

Some previous studies based on EUT has shown controversial results, the hypotheses of proportional taxation of declared income associated with a penalty on dissimulated income $\mathrm{q}(\mathrm{I}-\mathrm{x})$ are the essential hypothesis of the model of Allingham and Sandmo (1972). In this context, the taxpayer chooses the amount of income to declare, $x$, in order to maximize his expected utility. The results obtained show that increasing the penalty has a positive incentive on taxpayer to be honest in his tax report. However, the variation in declared income compared to the level of taxation ' $t$ ' is undetermined in the Model of Allingham and Sandmo (1972). The question is: Does the proportion of reported income increases as disposable income? This indetermination was lifted by (Yitzhaki 1974), he considered the problem of tax fraud as a framework similar to that defined by Allingham and Sandmo (1972), but in which the penalty, denoted $\mathrm{q}$, concerns specifically the evaded tax: $t^{*}(\mathrm{I}-\mathrm{x})$. the result obtained by Yitzhaki shows that tax fraud decrease when the tax rate increase. But empirical literature (Cebula and Feige, 2011) shows that there is a positive relationship between tax rate and tax fraud.

Based on the assumptions of the model of Allingham and Sandmo (1972; Bazart, 2002) showed that tax fraud decreases when real income rises. But tax administration cannot detect all the anomalies or omissions of taxpayers. This result represents a special case for our proposal model with an effectiveness of $100 \%$ or $r=1$. 
Table 1. (Previous Models) Matrix q*r (penalty rate *tax audit effectiveness)

\begin{tabular}{|c|c|c|c|c|c|c|c|c|c|c|c|}
\hline Q & 1 & 1.1 & 1.2 & 1.3 & 1.4 & 1.5 & 1.6 & 1.7 & 1.8 & 1.9 & 2 \\
\hline $\mathrm{R}$ & 1 & 1.0 & 1.0 & 1.0 & 1.0 & 1.0 & 1.0 & 1.0 & 1.0 & 1.0 & 1 \\
\hline$r^{*} q$ & 1 & 1.1 & 1.2 & 1.3 & 1.4 & 1.5 & 1.6 & 1.7 & 1.8 & 1.9 & 2 \\
\hline
\end{tabular}

Table 2. (Our model) Matrix $\mathrm{q}^{*} \mathrm{r}$ (penalty rate *tax audit effectiveness)

\begin{tabular}{|c|c|c|c|c|c|c|c|c|c|c|c|}
\hline $\mathrm{q} / \mathrm{R}$ & 1.0 & 1.1 & 1.2 & 1.3 & 1.4 & 1.5 & 1.6 & 1.7 & 1.8 & 1.9 & 2.0 \\
\hline 0.0 & 0.0 & 0.0 & 0.0 & 0.0 & 0.0 & 0.0 & 0.0 & 0.0 & 0.0 & 0.0 & 0.0 \\
\hline 0.1 & 0.1 & 0.11 & 0.12 & 0.13 & 0.14 & 0.15 & 0.16 & 0.17 & 0.18 & 0.19 & 0.2 \\
\hline 0.2 & 0.2 & 0.22 & 0.24 & 0.26 & 0.28 & 0.3 & 0.32 & 0.34 & 0.36 & 0.38 & 0.4 \\
\hline 0.3 & 0.3 & 0.33 & 0.36 & 0.39 & 0.42 & 0.45 & 0.48 & 0.51 & 0.54 & 0.57 & 0.6 \\
\hline 0.4 & 0.4 & 0.44 & 0.48 & 0.52 & 0.56 & 0.6 & 0.64 & 0.68 & 0.72 & 0.76 & 0.8 \\
\hline 0.5 & 0.5 & 0.55 & 0.6 & 0.65 & 0.7 & 0.75 & 0.8 & 0.85 & 0.9 & 0.95 & 1.0 \\
\hline 0.6 & 0.6 & 0.66 & 0.72 & 0.78 & 0.84 & 0.9 & 0.96 & 1.02 & 1.08 & 1.14 & 1.2 \\
\hline 0.7 & 0.7 & 0.77 & 0.84 & 0.91 & 0.98 & 1.05 & 1.12 & 1.19 & 1.26 & 1.33 & 1.4 \\
\hline 0.8 & 0.8 & 0.88 & 0.96 & 1.04 & 1.12 & 1.2 & 1.28 & 1.36 & 1.44 & 1.52 & 1.6 \\
\hline 0.9 & 0.9 & 0.99 & 1.08 & 1.17 & 1.26 & 1.35 & 1.44 & 1.53 & 1.62 & 1.71 & 1.8 \\
\hline 1.0 & 1.0 & 1.1 & 1.2 & 1.3 & 1.4 & 1.5 & 1.6 & 1.7 & 1.8 & 1.9 & 2.0 \\
\hline
\end{tabular}

The model of Allingham and Sandmo (1972) as it is given in Equation 1 became:

$$
E U=(1-p) U\left(I_{n d}\right)+p U\left(I_{d}\right)
$$

With:

$$
I_{d}=I-t x-r q(I-x)
$$

and:

$$
I_{n d}=I-t x
$$

The taxpayer chooses the amount of income to report, $\mathrm{x}$, in order to maximize his expected utility and the conditions for maximum are: (The second order condition is denoted $\mathrm{D})$ :

$$
\begin{aligned}
& t\left[-(1-p) U^{\prime}\left(I_{n d}\right)+p(r q-1) U^{\prime}\left(I_{d}\right)\right]=0 \\
& D=t^{2}\left[(1-p) U^{\prime \prime}\left(I_{n d}\right)+p(r q-1)^{2} U^{\prime \prime}\left(I_{d}\right)\right.
\end{aligned}
$$

Proposal: For a given level of penalty $\mathrm{q}$ and given an effectiveness of tax audit $r$, the tax fraud would decline when real income rises if $(r q>=1)$ and it increases in function of income in the opposite case.

Demonstration:

We can easily prove that:

$$
\frac{\partial x}{\partial I}=-\frac{t(1-p) U^{\prime}\left(I_{n d}\right)\left[A\left(I_{n d}\right)-(1-r q) A\left(I_{d}\right)\right]}{D}
$$

With respect to the condition of the model, if $(r q \geq 1)$, so we have: $\frac{\partial x}{\partial I} \geq 0$
We conclude that for a given level of penalty $q$ and given an efficiency of tax audit $r$, the tax fraud would decline when real income rises if $r q \geq 1$ (see Fig. 2) and it increases in function of income in the opposite case.

From Table 1, we can notice that in previous models, the effectiveness ' $r$ ' is equal to $1(100 \%)$ which represent a special case of our model (Table 2), the value of ' $r$ ' is between 0 and 1 .

\section{Application-Moroccan Case}

We project our theoretical results on the Moroccan case to assess the effectiveness of the last legislative decisions in fiscal terms.

Taking the case of Morocco, for each correction of the tax base after fiscal control, besides the payment of the tax evaded, taxpyers will pay as a minimum $30 \%$ of the evaded tax. However, if we increase the penalty and keep the same level of effectiveness of tax audits, taxpayers who have high income are more honest than those with lower incomes. This result is quite logical; for a low income, even if we increase the punishment, its effect on disposable income of the taxpayer fraud is minimal.

Generally, in morocco, based on experts' confirmation from tax department, the effectiveness of fiscal control is less than $80 \%$, so regarding our theoretical result, tax fraud increases with income. Which mean that the Moroccan government should focus their effort on big companies in order to reduce the effect of tax fraud. However, among the latest legislative decisions of Moroccan government is the decrease of tax rate from 30 to $10 \%$ for very small companies. We notice that medium and big companies are not concerned by this decision.

We conclude that if the target of the government is increasing tax revenue due to tax audit, the government should select big and medium companies for control. 
However, if the target is enlarge tax base and attract the informal sector to integrate the formal economy, the legislative decision should take time in consideration; instead of very small and medium companies, the reduce of tax rate from 30 to $10 \%$ must concern new companies.

Tax fraud is the emerging issues for concern where this issue is becoming a global phenomenon that should be a concern for the state authorities, in particular the tax authorities, because it would threaten state tax revenues. For that reason, it is necessary for the tax authorities to carry out effective strategies to combat and prevent tax fraud. Tax fraud has become one of the "enemy" who must be the primary concern of a state tax authorities for possible onshore materially reduce tax revenues. Therefore, it is first important to understand the meaning of tax fraud. In taxation, there are a number of negative behaviors of taxpayers who may be performed to obtain tax benefits.

\section{Tax Actors}

Tax evasion remains a shared responsibility between different tax actors that tax authorities must take into account:

Business people and stakeholders are able to control themselves each to the lack of benefits illegally.

Supposedly the company's internal accountants and public accountants remain objective and independent and not affected by the management. Internal accountant should be responsible directly to the owner and not its management company, as this can reduce the pressure faced by internal accountants.

The development of social responsibility:

Business persons are required to care about the state of society. Thus, under any circumstances the businesses should be able to develop and manifest the attitude of responsibility towards the local community in their business environment.

The importance of ethics education for accountants as a provision in the face of potential fraud: Ethics violations will continue to occur if there is no deep understanding of the importance of accountants to adhere to professional ethics. It could be that they do not know the impact of the fraud which they did. One way to reduce the number of accountants who deviate and instill awareness of the importance of applying the code of ethics is to do intensive socialization on professionalism and code of ethics of accountants in the work environment.

\section{The Government of Morocco}

The government should tighten supervision of tax to companies large and not selective in resolving tax evasion. The government should implement severe penalties for companies that darken taxes and severely punish the persons who receive bribes and companies should be aware of their tax obligations. Multinational corporations who intentionally proved not fulfill the obligations of economic, legal and social operating license can be revoked and banned from operating in Morocco. The first important thing in order to successfully fight against tax fraud is a good and strong cooperation between the authorities of the State. This means that not only the cooperation between the tax authorities, but also the cooperation between the tax authorities with other authorities, such as the National Police, Bank, Customs and Excise. Moreover, for intergovernmental cooperation, it would also be beneficial if there is cooperation between the government and other parties that have information about tax fraud, such as employees of a company that does the tax fraud.

\section{Law Enforcement}

If the law is applied effectively, both the taxpayer and the government will be reluctant to act against the law. On the other hand, in an environment of weak law enforcement, taxpayer "rogue" will try to find loopholes in the law and abuse. Furthermore, the authorities, such as tax officials, police or other authorities, also will try to take advantage of the situation to their own advantage, thus, it will create an environment conducive to collusion and corruption. For that reason, it is necessary to have a well-established law enforcement to tackle and prevent tax fraud.

\section{Summary and Concluding Remarks}

The Results of our study do not show that EUT Model is better than PT Model contrary to what it is stated by some other authors. We conclude that each Model can help to understand taxpayers' behavior based on its own initial assumptions. We notice that there is complementary relationship between those two Models.

The models stated above concerning the EUT, represent a special case of our model. Where tax audit effectiveness is equal to $1(100 \%)$, our model give the same results as others model, but in the reality tax audit effectiveness can't be at its maximal value.

Tax administration is always trying to find and control companies that represent a major risk in terms of tax fraud. The result of our work will be a guide for the selected companies that will be controlled by referring to the parameters of the tax system that is in place. Moreover, based on this finding and by applying it to the Moroccan case that represent a low effectiveness in terms of tax audits and that sanction policy are fairly flexible. It is important to address the control to big businesses. Yet, such companies represent a negligible percentage of the overall tax population and a concentrated and continuous auditing will disrupt their development and their growth, especially that their 
contribution exceeds $80 \%$ of total tax revenues. On the other hand, the audit of small and very small enterprises is expensive for the tax administration because it needs to increases the number of files to audit and increase also the number of auditors as well.

We can also notice that tax audit is not enough to avoid tax evasion, tax authorities must look for other tools to struggle fraud, especially using advanced tools of risk analysis for planning files to be controlled. We propose that tax authority should perceive the fraudulent taxpayers not only as robbers but also as clients; we suggest the improvement of the relationship between taxpayers and the government in order to create a climate of cooperation and trust.

\section{Acknowledgement}

We are grateful to anyone who has contributed in any way to the realization of this work. In particular our colleagues from General Directorate of Taxes of Morocco.

\section{Funding Information}

Our proposal model represent a solution to Ytzhaki puzzle. For a given level of penalty q and given an effectiveness of tax audit $r$, the tax fraud would decline when real income rises if $(\mathrm{rq}>=1)$ and it increases in function of income in the opposite case.

\section{Author's Contributions}

This study is the result of the full and equal collaboration of all the authors:

Farid Ameur: Ideas generation; literature review and model and mathematical design and equal contribution to result validation and discussion.

Mohamed Tkiouat: Ideas generation, Designing the methodology, mathematical validation and equal contribution to result validation and discussion.

\section{Conflict of Interest}

The author confirms that this article content has no conflict of interest.

\section{References}

Allingham, M.G. and A. Sandmo, 1972. Income tax evasion: A theoretical analysis. J. Public Econom., 1: 323-338. DOI: 10.1016/0047-2727(72)90010-2

Caplin, A. and J. Leahy, 2001. Psychological expected utility theory and anticipatory feelings. Q. J. Econom., 116: 55-80. DOI: 10.1162/003355301556347
Bazart, C., 2002. «The behavior of tax fraud: Taxpayers facing tax administration». French J. Econom., 16: 171-212.

Cebula, R. and E.L. Feige, 2011. America's underground economy: Measuring the size, growth and determinants of income tax evasion in the U.S. Munich University Library.

Dhami, S. and A. Al-Nowaihi, 2007. Why do people pay taxes? Prospect theory versus expected utility theory. J. Econom. Behavior Organ., 64: 171-192. DOI: $10.1016 /$ j.jebo.2006.08.006

Ameur, F. and M. Tkiouat, 2012. Taxpayers fraudulent behavior modeling the use of datamining in fiscal fraud detecting Moroccan case. Applied Math., 3: 1207-1213. DOI: 10.4236/am.2012.310176

Ameur, F. and M. Tkiouat, 2014. Expected utility theory vs prospect theory taxpayers' fraudulent behaviour modelling-Moroccan case. Int. Res. J. Finance Econom., 121: 76-87.

Ameur, F. and M. Tkiouat, 2015. Determinants of tax fraud: Experience from Morocco. Eur. J. Econom. Finance Admin. Sci., 78: 100-110.

Hashimzade, N., G.D. Myles and B. Tran-Nam, 2012. Applications of behavioural economics to tax evasion. J. Econom. Surveys, 27: 941-977. DOI: $10.1111 /$ j.1467-6419.2012.00733.x

Kahneman, D. and A. Tversky, 1979. Prospect theory: An analysis of decision under risk. Econometrica, 47: 263-291. DOI: $10.2307 / 1914185$

Koskela, 1983. On the shape of tax schedule, the probability of detection and the penalty schemes as deterrents to tax evasion. Public Finance, 38: 70-80.

Piolatto, A. and M.D. Rablen, 2013. Prospect theory and tax evasion: A reconsideration of the yitzhaki puzzle. Theory Decis.

Yitzhaki, S., 1974. A Note on income tax evasion: A theoretical analysis. J. Public Econom., 3: 201-220. DOI: $10.1016 / 0047-2727(74) 90037-1$ 